\title{
Irradiation-Induced Cardiac Connexin-43 and miR-21 Responses Are Hampered by Treatment with Atorvastatin and Aspirin
}

\author{
Csilla Viczenczova ${ }^{1}$, Branislav Kura ${ }^{1}$, Tamara Egan Benova ${ }^{1}$, Chang Yin ${ }^{2}$, Rakesh C. Kukreja ${ }^{2}$, \\ Jan Slezak ${ }^{1}$, Narcis Tribulova ${ }^{1}$ and Barbara Szeiffova Bacova ${ }^{1, *}$ \\ 1 Institute for Heart Research, Center of Experimental Medicine, Slovak Academy of Sciences, \\ Bratislava 841 04, Slovak Republic; viczencz.csilla@gmail.com (C.V.); branislav.kura@savba.sk (B.K.); \\ tamara.benova@savba.sk (T.E.B.); jan.slezak@savba.sk (J.S.); narcisa.tribulova@savba.sk (N.T.) \\ 2 Division of Cardiology, Medical College of Virginia, Virginia Commonwealth University, \\ Richmond, VA 23298, USA; rakesh@vcu.edu (C.Y.); rakesh.kukreja@vcuhealth.org (R.C.K.) \\ * Correspondence: barbara.bacova@savba.sk; Tel.: +421-2-3229-5419
}

Received: 9 March 2018; Accepted: 5 April 2018; Published: 10 April 2018

\begin{abstract}
Radiation of the chest during cancer therapy is deleterious to the heart, mostly due to oxidative stress and inflammation related injury. A single sub-lethal dose of irradiation has been shown to result in compensatory up-regulation of the myocardial connexin-43 (Cx43), activation of the protein kinase $\mathrm{C}(\mathrm{PKC})$ signaling along with the decline of microRNA (miR)-1 and an increase of miR-21 levels in the left ventricle (LV). We investigated whether drugs with antioxidant, anti-inflammatory or vasodilating properties, such as aspirin, atorvastatin, and sildenafil, may affect myocardial response in the LV and right ventricle (RV) following chest irradiation. Adult, male Wistar rats were subjected to a single sub-lethal dose of chest radiation at $25 \mathrm{~Gy}$ and treated with aspirin ( $3 \mathrm{mg} /$ day), atorvastatin $(0.25 \mathrm{mg} /$ day), and sildenafil ( $0.3 \mathrm{mg} /$ day) for six weeks. Cx43, $\mathrm{PKC} \varepsilon$ and $\mathrm{PKC} \delta$ proteins expression and levels of miR-1 as well as miR-21 were determined in the LV and RV. Results showed that the suppression of miR-1 was associated with an increase of total and phosphorylated forms of $\mathrm{C} \times 43$ as well as PKC $\varepsilon$ expression in the LV while having no effect in the RV post-irradiation as compared to the non-irradiated rats. Treatment with aspirin and atorvastatin prevented an increase in the expression of Cx43 and PKC $\varepsilon$ without change in the miR-1 levels. Furthermore, treatment with aspirin, atorvastatin, and sildenafil completely prevented an increase of miR-21 in the LV while having partial effect in the RV post irradiation. The increase in pro-apoptotic PKC $\delta$ was not affected by any of the used treatment. In conclusion, irradiation and drug-induced changes were less pronounced in the RV as compared to the LV. Treatment with aspirin and atorvastatin interfered with irradiation-induced compensatory changes in myocardial $\mathrm{C} \times 43$ protein and miR-21 by preventing their elevation, possibly via amelioration of oxidative stress and inflammation.
\end{abstract}

Keywords: irradiation; heart; connexin-43; miR-1; miR-21; atorvastatin; aspirin

\section{Introduction}

Cardiovascular injury due to radiation is the most common cause of adverse events among cancer survivors [1,2]. Key factors responsible for the establishment of cardiovascular injury, i.e., oxidative stress, inflammation, and epigenetic modifications, have been linked to potential treatments and been recently described [1,2]. Ionizing radiation induces oxidative stress and causes changes in the expression of several microRNAs (miRNA)s, including miR-1 and miR-21. An increase of miR-21 is involved in myocardial hypertrophy [3,4] and fibrosis [5]. An increase in miR-21 has also been 
associated with the up-regulation of the protein kinase C (PKC) $\delta$ [6], which is also implicated in tissue remodeling. Fibrosis and necrosis were reduced by the treatment with a free radical-scavenging component such as melatonin [7]. However, molecular mechanisms of the irradiation induced injury are unknown and there is currently a lack of treatment strategies.

Cardiac connexin-43 (Cx43) channels are essential for coordinated heart function because they ensure electrical coupling and direct intercellular communication. We and others $[6,8]$ have shown that a single sub-lethal dose of irradiation results in up-regulation of $\mathrm{Cx} 43$, which has been associated with the protection of the heart against malignant arrhythmias [9] and infarction [10]. An increase in myocardial Cx43 expression and its active phosphorylated forms has been shown to be associated with the suppression of miR-1 (which regulates GJA1 gene transcription for Cx43) and the enhancement of $\mathrm{PKC} \varepsilon$ (which phosphorylates Cx43) [6]. It appears that these early post-irradiation related myocardial alterations, including up-regulation of $\mathrm{Cx} 43$, are most likely compensatory responses of the heart to maintain its normal function [10-12]. Since irradiation induces inflammation and oxidative stress [12], we hypothesized that compounds exerting anti-inflammatory and antioxidant actions would interfere with irradiation-induced compensatory responses. To this context, we considered several drugs, which included acetylsalicylic acid (aspirin), a non-selective inhibitor of cyclooxygenase- 1 and cyclooxygenase-2, which prevents formation of pro-inflammatory prostaglandins and thromboxanes. Antioxidant properties of acetylsalicylic acid are attributed to its ability of inhibiting lipid peroxidation and DNA damage [13]. Atorvastatin is widely used for treatment of human dislipidemia due to inhibition of the 3-hydroxy-3-methylglutaryl coenzyme A reductase. In addition, its pleiotropic effects are associated with anti-inflammatory and antioxidative actions [14] as well as promoting the availability of vascular nitric oxide [15]. Sildenafil, the inhibitor of phosphodiestherase 5, is used for its vasodilatation and activation of nitric oxide [16].

Our goal was to demonstrate whether treatment with the drugs targeting oxidative stress and inflammation might result in attenuation of irradiation induced myocardial compensatory responses previously reported $[6,10]$. In particular, we examined myocardial changes in Cx43, PKC, miR-1 and miR-21 in rats exposed to single chest irradiation.

\section{Results}

\subsection{Main Characteristics of Experimental Rats}

Comparing to non-irradiated rats, the body, heart, and left ventricular weight were significantly decreased in irradiated animals after six weeks. On the other hand, irradiation did not alter the right ventricular weight. Treatment with selected drugs also had no effect on these biometric parameters in any treated group, except for the heart weight in post-irradiated + sildenafil group. Data are summarized in the Table 1.

Table 1. Biometric parameters registered in control and irradiated Wistar rats.

\begin{tabular}{ccccc}
\hline GROUP & BW $(\mathbf{g})$ & HW $(\mathbf{g})$ & LVW $(\mathbf{g})$ & RVW $(\mathbf{g})$ \\
\hline C & $344.22 \pm 28.40$ & $0.89 \pm 0.11$ & $0.36 \pm 0.07$ & $0.09 \pm 0.02$ \\
C-A & $382.61 \pm 32.19$ & $0.92 \pm 0.09$ & $0.39 \pm 0.04$ & $0.12 \pm 0.01$ \\
C-AT & $371.01 \pm 20.45$ & $0.87 \pm 0.07$ & $0.37 \pm 0.04$ & $0.10 \pm 0.02$ \\
C-S & $363.63 \pm 23.93$ & $0.90 \pm 0.10$ & $0.39 \pm 0.04$ & $0.11 \pm 0.02$ \\
I & $252.24 \pm 14.31^{\mathrm{a}}$ & $0.83 \pm 0.05$ & $0.25 \pm 0.04^{\mathrm{a}}$ & $0.10 \pm 0.04$ \\
I-A & $227.41 \pm 26.47^{\mathrm{c}}$ & $0.73 \pm 0.09^{\mathrm{c}}$ & $0.24 \pm 0.02^{\mathrm{c}}$ & $0.11 \pm 0.03$ \\
I-AT & $253.23 \pm 31.82^{\mathrm{c}}$ & $0.77 \pm 0.08$ & $0.27 \pm 0.03^{\mathrm{c}}$ & $0.13 \pm 0.03$ \\
I-S & $233.62 \pm 14.50^{\mathrm{c}}$ & $0.67 \pm 0.05^{\mathrm{b}, \mathrm{c}}$ & $0.23 \pm 0.02^{\mathrm{c}}$ & $0.12 \pm 0.03$
\end{tabular}

BW-body weight; HW—heart weight; LVW—left ventricular weight; RVW—right ventricular weight; C—control non-irradiated; C-A—control + aspirin; C-AT—control + atorvastatin; C-S—control + sildenafil; I-irradiated rats; I-A-irradiated + aspirin; I-AT-irradiated + atorvastatin; I-S-irradiated + sildenafil. Results are the mean \pm SD of 6 hearts. ${ }^{a} p<0.05$ vs. C (C vs. C-A, C-AT, C-S, I); ${ }^{b} p<0.05$ vs. I (I vs. I-A, I-AT, I-S); ${ }^{\mathrm{c}} p<0.05$ treated C vs. treated I (C-A vs. I-A; C-AT vs. I-AT; C-S vs. I-S). 


\subsection{Protein Expression of Myocardial Cx43 in Control and Irradiated Wistar Rats}

Western blot analysis showed that total Cx43 protein was increased in the LV $(p<0.05)$ and to a lesser extent in RV post-irradiation as compared to the non-irradiated group (Figure $1 A, B, D, E$ ). In parallel, the active phosphorylated forms of Cx43 were significantly increased in the LV and RV of irradiated rats versus the non-irradiated controls (Figure 1A,C,D,F). Treatment with aspirin and atorvastatin for six weeks (starting one day before irradiation) suppressed the elevation of the total as well as the phosphorylated forms of Cx43, significantly in the LV (Figure 1A-C) while having no effect in RV (Figure 1D-F) of post-irradiated animals. The administration of sildenafil had no significant effect on the irradiation-induced increase in myocardial Cx43, i.e., either on total levels or its phosphorylated forms after six weeks (Figure 1).

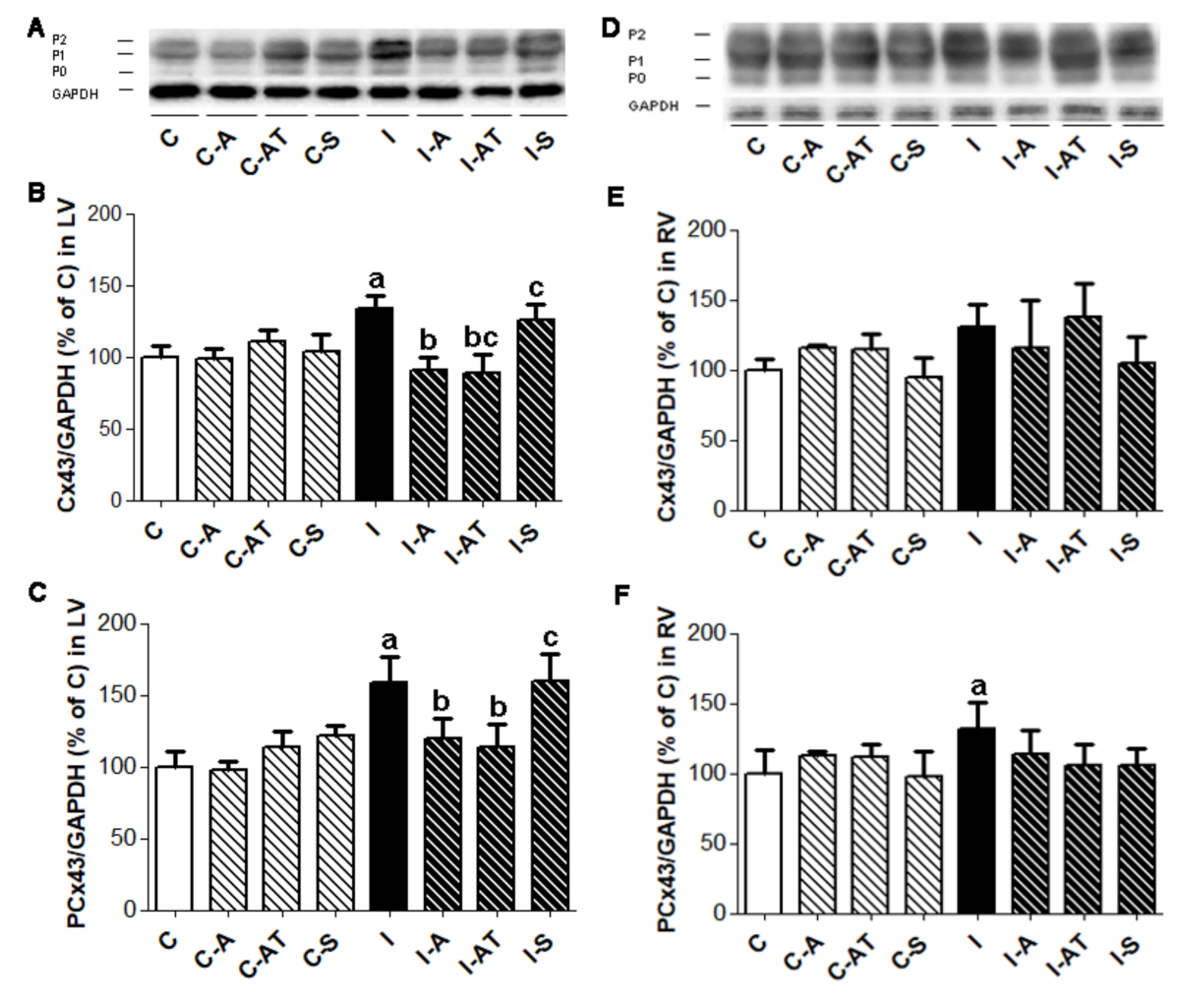

Figure 1. Representative immunoblots showing three forms of Cx43 (A,D) and densitometric quantification of total Cx43 expression (B,E), and its phosphorylated forms $(\mathbf{C}, \mathbf{F})$ normalized to GAPDH in the LV (left panel) and RV (right panel) of non-irradiated and post-irradiated Wistar rats with and without treatment. Abbreviations-P0: unphosphorylated form of Cx43; P1 and P2: phosphorylated forms of Cx43; GAPDH: housekeeper; C: control non-irradiated rats; C-A: control + aspirin; C-AT: control + atorvastatin; C-S: control + sildenafil; I: post-irradiated rats; I-A: post-irradiated + aspirin; I-AT: post-irradiated + atorvastatin; I-S: post-irradiated + sildenafil. Data are means \pm SD of 6 hearts. ${ }^{\mathrm{a}} p<0.05$ vs. C (C vs. C-A, C-AT, C-S, I); ${ }^{\mathbf{b}} p<0.05$ vs. I (I vs. I-A, I-AT, I-S); ${ }^{\mathrm{c}} p<0.05$ treated C vs. treated I (C-A vs. I-A; C-AT vs. I-AT; C-S vs. I-S).

\subsection{Expression of Protein Kinase Ce in Control and Irradiated Wistar Rats}

PKC $\varepsilon$ was significantly increased in the LV (Figure 2A,B) but not in the RV (Figure 2C,D) of rats following irradiation when compared to the non-irradiated controls. Six weeks of treatment with aspirin and atorvastatin following irradiation normalized PKC $\varepsilon$ in the LV (Figure 2A,B) while having no effect in the RV (Figure 2C,D). Treatment with sildenafil had no effect on the PKC $\varepsilon$ expression of the irradiated rats. There was no change in the expression of PKC $\varepsilon$ in non-irradiated rats following treatment with drugs (Figure 2). 
A

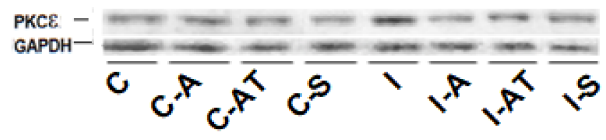

B

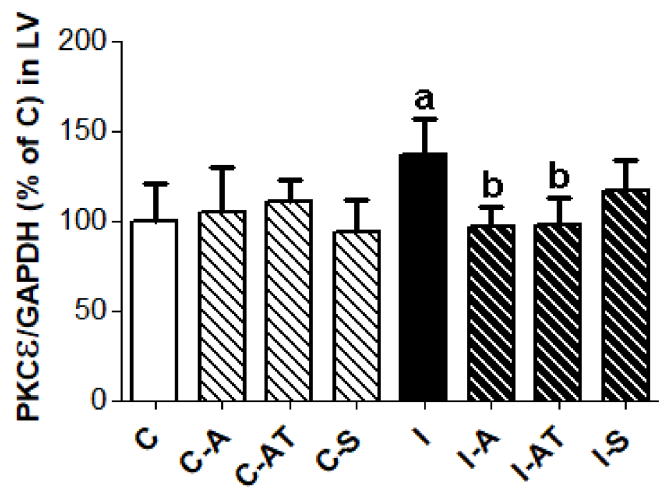

C

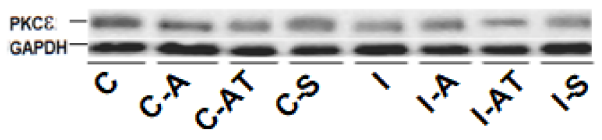

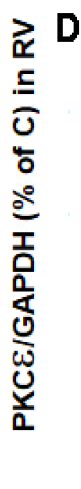

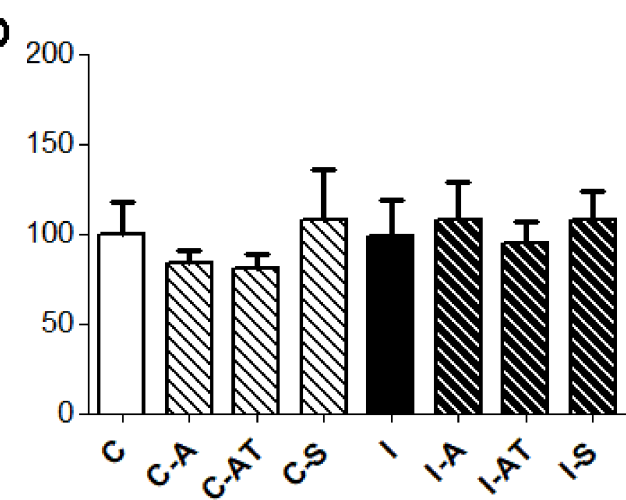

Figure 2. Representative immunoblots of $\mathrm{PKC} \varepsilon$ expression $(\mathbf{A}, \mathbf{C})$ and its quantitative evaluation normalized to GAPDH in the LV ((B), left panel) and RV ((D), right panel) of non-irradiated and post-irradiated Wistar rats with and without treatment. Abbreviations-PKC $\varepsilon$ : protein kinase $C$ epsilon; GAPDH: housekeeping protein; C: control non-irradiated rats; C-A: control + aspirin; C-AT: control + atorvastatin; C-S: control + sildenafil; I: post-irradiated rats; I-A: post-irradiated + aspirin; I-AT: post-irradiated + atorvastatin; I-S: post-irradiated + sildenafil. Data are means \pm SD of 6 hearts. a $p<0.05$ vs. C (C vs. C-A, C-AT, C-S, I); ${ }^{b} p<0.05$ vs. I (I vs. I-A, I-AT, I-S).

\subsection{Expression of Protein Kinase $C \delta$ in Control and Irradiated Wistar Rats}

Similar to PKCE, the myocardial expression of PKC (Figure 3) was increased in response to irradiation. The increase was significant in the LV (Figure 3A,B) while no change was observed in the RV (Figure 3C,D) when compared to the to non-irradiated controls. Treatment with drugs had no effect on the expression of PKC $\delta$ in the LV or RV in the irradiated and non-irradiated groups (Figure 3).

A

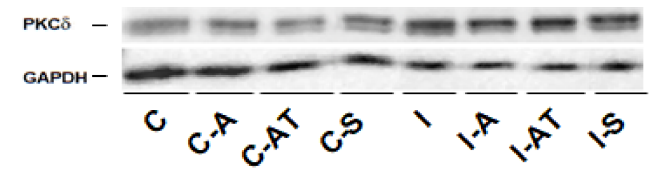

B

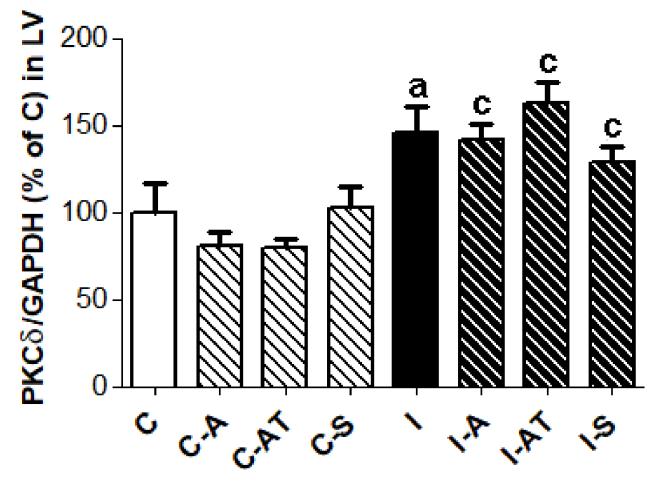

C

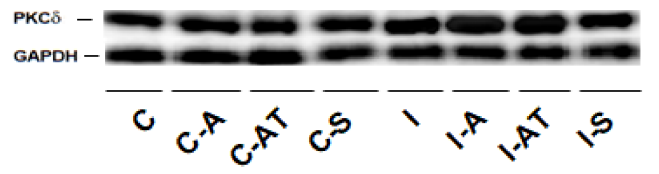

D

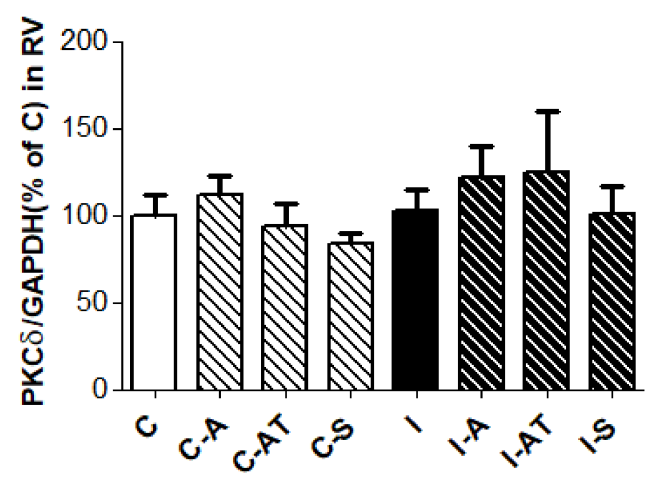

Figure 3. Representative immunoblots of $\mathrm{PKC} \delta$ expression $(\mathbf{A}, \mathbf{C})$ and quantitative evaluation normalized to GAPDH in the LV ((B), left panel) and RV ((D), right panel) of non-irradiated and post-irradiated Wistar rats. Abbreviations-PKC $\delta$ : protein kinase $\mathrm{C}$ delta; GAPDH: housekeeping protein; C: control non-irradiated rats; C-A: control + aspirin; C-AT: control + atorvastatin; C-S: control + sildenafil; I: post-irradiated rats; I-A: post-irradiated + aspirin; I-AT: post-irradiated + atorvastatin; I-S: post-irradiated + sildenafil. Data are means \pm SD of 6 hearts. ${ }^{a} p<0.05$ vs. C (C vs. C-A, C-AT, C-S, I); ${ }^{\mathrm{c}} p<0.05$ treated C vs. treated I (C-A vs. I-A; C-AT vs. I-AT; C-S vs. I-S). 


\subsection{Myocardial Expression of miR-1 in Control and Irradiated Wistar Rats}

miR-1 level decreased following six weeks after irradiation (Figure 4), which was signficant in the LV (Figure 4A) but not in the RV (Figure 4B). Treatment with the drugs had no significant effect on miR-1 level in post-irradiated as well as in non-irradiated groups (Figure 4).

A

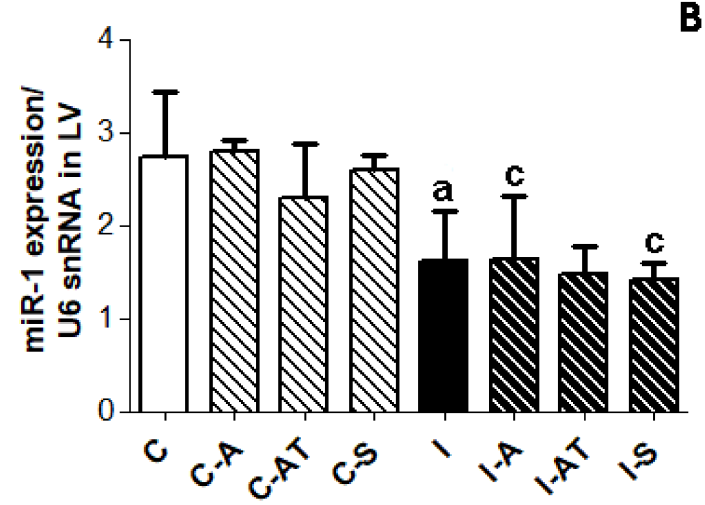

B

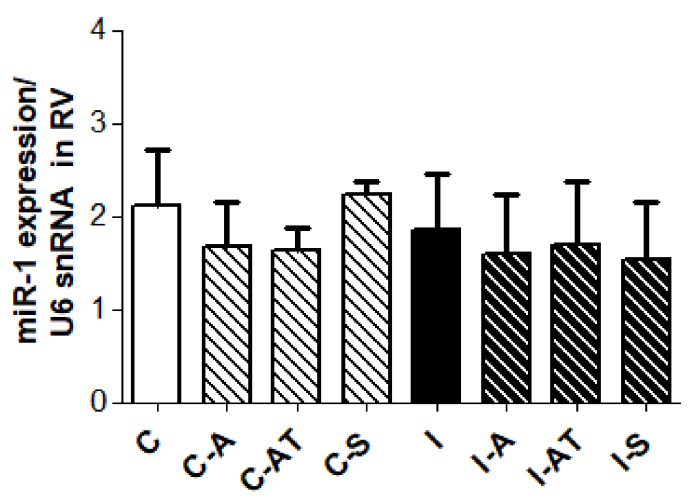

Figure 4. Myocardial expression of miR-1 in the LV ((A), left panel) and RV ((B), right panel) of non-irradiated and post-irradiated Wistar rats with and without treatment. Endogenous U6 small nuclear RNA (U6snRNA) was used to normalize miR-1. Abbreviations-C: control non-irradiated rats; C-A: control + aspirin; C-AT: control + atorvastatin; C-S: control + sildenafil; I: post-irradiated rats; I-A: post-irradiated + aspirin; I-AT: post-irradiated + atorvastatin; I-S: post-irradiated + sildenafil. Data are means \pm SD of 5 hearts. ${ }^{a} p<0.05$ vs. C (C vs. C-A, C-AT, C-S, I); ${ }^{c} p<0.05$ treated C vs. treated I (C-A vs. I-A; C-AT vs. I-AT; C-S vs. I-S).

\subsection{Expression of miR-21 in Control and Irradiated Wistar Rats}

The expression of myocardial miR-21 was significantly increased in both the LV and RV of the post-irradiated rats compared to the non-irradiated controls (Figure 5). Six weeks of treatment with the selected drugs significantly suppressed miR-21 expression in the left (Figure 5A), although to a lesser extent in the RV (Figure 5B) following irradiation. There was no effect of drugs on miR-21 levels in the non-irradiated control groups (Figure 5).

A

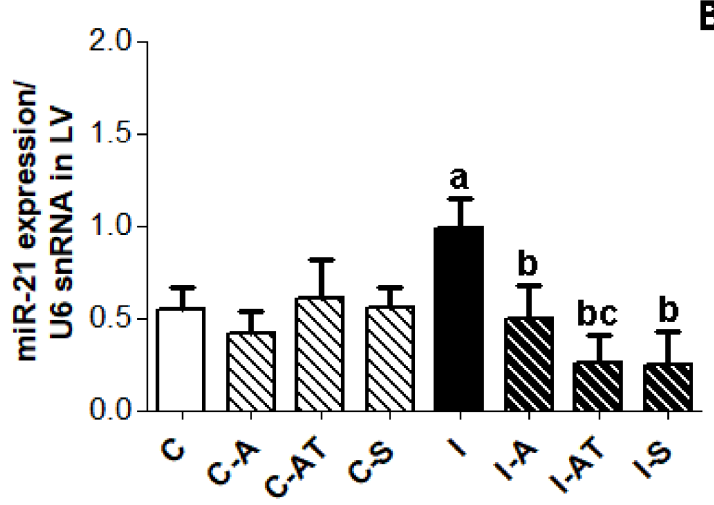

B

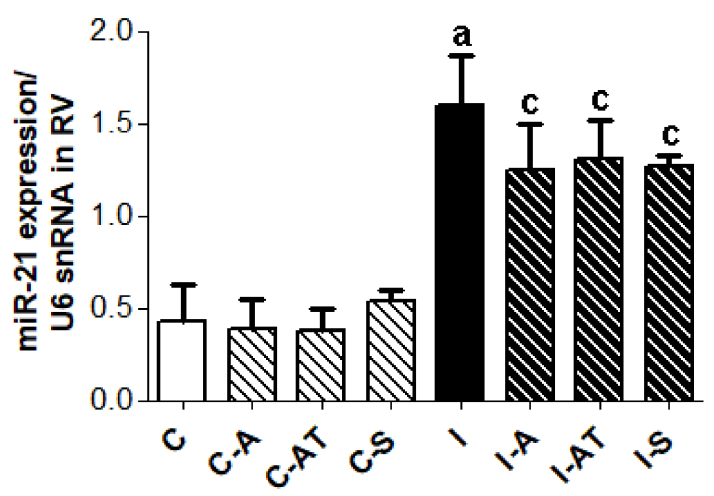

Figure 5. Myocardial expression of miR-21 in the LV (A) and RV (B) of non-irradiated and post-irradiated Wistar rats with and without treatment. Endogenous U6 small nuclear RNA (U6snRNA) was used to normalize miR-21. Abbreviations-C: control non-irradiated rats; C-A: control + aspirin; C-AT: control + atorvastatin; C-S: control + sildenafil; I: post-irradiated rats; I-A: post-irradiated + aspirin; I-AT: post-irradiated + atorvastatin; I-S: post-irradiated + sildenafil. Data are means \pm SD of 5 hearts. ${ }^{a} p<0.05$ vs. C (C vs. C-A, C-AT, C-S, I); ${ }^{b} p<0.05$ vs. I (I vs. I-A, I-AT, I-S); ${ }^{c} p<0.05$ treated C vs. treated I (C-A vs. I-A; C-AT vs. I-AT; C-S vs. I-S). 


\section{Discussion}

In the present study, we showed that exposure of rats to a single dose of chest irradiation at 25 Gy caused up-regulation in the expression of Cx43, PKC $\varepsilon$, and PKC $\delta$ in the LV following six weeks. In parallel, miR-1, which is known to repress GJA1 for Cx43 [3,6] was decreased. While miR-21, which is involved in myocardial remodeling and apoptosis [3,6], was increased following irradiation. These results are in accordance with our previous findings $[6,10]$ and in line with the reported enhancement of myocardial Cx43 protein and mRNA expression found in the rabbit heart in response to heavy ion radiation [8,9]. Importantly, these alterations were associated with protection of the heart against arrhythmia and infarction $[8,10]$.

In the present study, we have also demonstrated that irradiation did not induce significant changes in the expression of total $\mathrm{Cx} 43$ in the RV, although there was a trend towards an increase. This may be in part due to the miR-1, which was not changed in the RV in contrast to its significant suppression associated with the enhancement of Cx43 in the LV. Furthermore, neither PKC $\varepsilon$ nor PKC $\delta$ expression was altered in the RV unlike its significant elevation in LV following irradiation. Whether such distinct responses to irradiation in the LV and RV have any relationship with functional, metabolic, structural, and other differences of the heart chambers $[17,18]$ needs to be investigated. Chamber related differences in Cx43 and PKC expression in response to altered thyroid status have been previously suggested [19]. A higher metabolic rate and mechanical load of the LV seems to be more prone to oxidative stress and injury. Nevertheless, our results suggest that cardiac response to chest irradiation is associated with the up-regulation of myocardial Cx43 connected with the suppression of miR-1 and enhanced PKC $\varepsilon$ and PKC $\delta$ signaling in the LV but not in the RV. On the other hand, the expression of miR-21 was significantly increased in both the LV and RV following irradiation. It is possible that the anti-apoptotic [20] and proliferation promoting effects of miR-21 [5] may be pro-survival to cardiac tissue during the early period in response to radiation-induced injury.

Our results also show that treatment of the irradiated rats with aspirin and atorvastatin prevented up-regulation of Cx43, i.e., its total and phosphorylated forms in the LV. Interestingly, none of the drugs reduced the level of miR-1 in the LV following irradiation. These data suggest that apart from the miR-1, other post-translational factors may modulate Cx43 levels in response to irradiation. Neither atorvastatin nor aspirin had any effect on the basal myocardial expression of Cx43 in the non-irradiated control rats.

The question arises, how aspirin or atorvastatin may affect changes in myocardial $\mathrm{Cx} 43$ protein levels induced by single chest irradiation? Considering that both compounds exert protection from oxidative stress and inflammation-the important culprits in irradiation-induced cardiac injury $[1,2]-i$ it is reasonable to speculate that these drugs may suppress these processes. If so, then cardiac stress would be attenuated and a subsequent compensatory response (most likely mediated by free radicals and pro-inflammatory molecules signaling) will be reduced. Indeed, the administration of antioxidants and/or scavengers of free radicals, such as hesperidin [21], melatonin [7] or selenium [22] prior to irradiation attenuated oxidative stress, inflammation, and cardiomyocyte necrosis. The potential use of statins as radioprotective agents has been recently reviewed, where signaling pathways targeting pro-inflammatory NF- $\mathrm{kB}$ might be implicated [1]. In support of this concept, it should be noted that unlike aspirin and atorvastatin, treatment with sildenafil (dominant vasculo-protective drug) did not affect the myocardial Cx43 levels in irradiated rats. Moreover, aspirin and atorvastatin but not sildenafil reduced expression of TNF- $\alpha$ in irradiated rats in our model, as reported previously [23].

In general, oxidative stress and/or inflammation contribute to the impairment of intercellular communication due to the acceleration of $\mathrm{C} \times 43$ and $\mathrm{C} \times 43$ interacting proteins that are in degradation and/or dysfunction [24]. Consequently, down-regulation of Cx43 due to chronic redox disorders and subclinical inflammation often accompanies cardiovascular disease $[25,26]$. On the other hand, acute heart injury (e.g., intermittent ischemia) triggers endogenous pro-survival molecular pathways, including up-regulation of $\mathrm{C} \times 43$, to protect heart function [27]. It appears that the 
heart may respond to stressors by compensatory/adaptive (such as up-regulation of Cx43) and by maladaptive/decompensatory changes (down-regulation of Cx43). Accordingly, enhanced Cx43 level observed in the compensatory hypertrophy was induced by pressure overload, while reduced Cx43 occurred in the decompensatory state [25].

Our results also show that the treatment of irradiated rats with aspirin and atorvastatin normalized the myocardial expression of $\mathrm{PKC} \varepsilon$, which is associated with the expression of phosphorylated forms of $\mathrm{Cx} 43$. These results suggest that oxidative stress and inflammation may modulate myocardial $\mathrm{PKC} \varepsilon$, signaling and its cardioprotective role as shown in various conditions [28]. Interestingly, treatment did not affect elevated myocardial PKC $\delta$ expression, i.e., its pro-hypertrophic signaling in irradiated rat heart. However, the expression of pro-fibrotic miR-21 was significantly decreased in the left heart ventricle by all tested drugs. Of note, miR-21 has been shown up-regulated in human fibroblast cells due to various stress-inducing conditions, including radiation $[3,29]$. Thus, more attention should be paid to elucidate the possible anti-fibrotic effects of atorvastatin, aspirin, and perhaps sildenafil. Importantly, microRNA-21 has been reported as a novel promising target in cancer radiation therapy [20] and atorvastatin was shown to suppress expansive remodeling by inhibition of macrophage infiltration [30].

Taken together, we assume that protection of the heart from oxidative stress and inflammation by appropriate drugs, including aspirin and atorvastatin or nonpharmacological compounds like melatonin [7], omega-PUFA [31] may counteract compensatory responses and attenuate adverse consequences of chest irradiation.

\section{Materials and Methods}

Animal experiments were approved by the Animal Research and Care Committee of the Institute for Heart Research, Slovak Academy of Sciences-Project 1873/11-221/3, approved on 30 September 2011 and in accordance with the rules issued by the State Veterinary Administration of the Slovak Republic, legislation No 289/2003. Rats were maintained on a 12:12 h's light/dark cycle with access to standard pellet and water ad libitum.

\subsection{Experimental Model of Irradiation Induced Cardiac Injury}

Three-month-old male Wistar rats were randomly divided into irradiated $(n=24)$ and non-irradiated $(n=24)$ groups. Rats were anesthetized with Narketan $(115 \mathrm{mg} / \mathrm{kg}$ body weight $)$ followed by myorelaxant Xylan ( $1 \mathrm{mg} / \mathrm{kg}$ body weight) and exposed to a single dose of $25 \mathrm{~Gy}$ of ionizing radiation given locally on mediastinum at the area of the heart using the electron linear accelerator UELR 5-1S (Producer NIIEFA St. Petersburg, RF, Russia), as described previously [6]. Control animals were shielded with lead plates. Non-irradiated controls (C) and irradiated (I) rats were treated one day before, the day of irradiation, and for the next six weeks with aspirin (A; $3 \mathrm{mg} /$ day), atorvastatin (AT; $0.25 \mathrm{mg} /$ day) or sildenafil (S; $0.3 \mathrm{mg} /$ day) via a gastric tube. Doses of the drugs were calculated from the maximal therapeutic dose for humans in relation to the rat body weight.

At the end of the experiment, hearts were excised from the anesthetized animals (thiopental, $65 \mathrm{mg} / \mathrm{kg}$ body weight) followed by the registration of the whole heart as well as left (LV) and right ventricle (RV) weight. Frozen tissues from the heart ventricles were stored at $-80^{\circ} \mathrm{C}$ in freezer box and used for the analysis of $\mathrm{Cx} 43, \mathrm{PKC} \varepsilon$ and PKC $\delta$ expression by the Western blot method and for miR-1 and miR-21 expression analysis by qRT-PCR.

\subsection{Determination of Myocardial C $x 43, P K C \varepsilon$ and PKC $\delta$ Protein Expression}

The western blot analysis was performed as previously described [6]. Briefly, the ventricular samples ( $n=6$ per group) were powdered and solubilized in SB20 (20\% SDS, $10 \mathrm{mmol} / \mathrm{L}$ EDTA, $0.1 \mathrm{~mol} / \mathrm{L}$ tris(hydroxymethyl) aminomethane (TRIS), $\mathrm{pH} 6.8$ by sonicator UP $100 \mathrm{H}$ (Hielscher, Teltow, Germany). Total proteins (10-30 $\mu \mathrm{g}$ ) from each sample were separated in 10\% sodium dodecyl sulfate polyacrylamide gels, transferred onto a nitrocellulose membrane, and blocked with $5 \%$ non-fat dry milk 
in Tris-buffered saline. For the determination of $\mathrm{C} x 43$, the membrane was incubated with a primary rabbit polyclonal antibody (diluted 1:4000; Anti-Connexin 43 C 6219; Sigma-Aldrich, St. Louis, MO, USA). For PKC $\varepsilon$ and $\mathrm{PKC} \delta$ determination, the nitrocellulose membrane was incubated with primary rabbit polyclonal antibodies (PKC $\varepsilon$ Antibody, C-15: sc-214, Santa Cruz Biotechnology, Inc., PKC $\delta$ Antibody, C-17: sc-213, Santa Cruz Biotechnology, Inc., Santa Cruz, CA, USA) diluted 1:1000, overnight at $4{ }^{\circ} \mathrm{C}$, followed by further incubation for $1 \mathrm{~h}$ at room temperature with a secondary donkey antibody (peroxidase-labeled anti-rabbit, 1:2000, Amersham Biosciences, Piscataway, NJ, USA). After ECL visualization, the densitometric analysis by Carestream Molecular Imaging Software (version 5.0, Carestream Health, New Haven, CT, USA.) was done using a KODAK In-Vivo Multispectral System FX. The measured values were normalized to the expression of GAPDH (glyceraldehyde-3-phosphate dehydrogenase) serving as a control [6].

\subsection{Estimation of Myocardial miR-1 and miR-21 Levels}

miR reverse transcription and TaqMan-based qRT-PCR analysis were performed as previously reported [6]. Total RNA including small RNA was isolated from the frozen ventricular tissue of the non-irradiated ( $n=5$ per group) and irradiated ( $n=5$ per group) Wistar rats using a miRNA mini kit according to the manufacturer's protocol (QIAGEN Sciences, Germantown, MD, USA). The concentration and purity of the isolated RNA was checked using a Nanodrop ND-1000 spectrophotometer (Agilent Technologies, Santa Clara, CA, USA). Briefly, $10 \mathrm{ng}$ of total RNA were subjected for reverse transcription reaction with miRNA specific RT primers using microRNA reverse transcription kit (Applied Biosystems, Foster City, CA, USA) in accordance to the manufacturer's instructions. Real time PCR was performed using a Roche Light cycler 480 II (Roche Applied Science, Indianapolis, IN, USA). TaqMan miRNA assay probe (Applied Biosystems, Foster City, CA, USA) was applied to determine the expression level of miR-1 and miR-21. Endogenous U6 small nuclear RNA was used to normalize RNA content. Reverse transcription was performed using stem loop specific microRT primers under the following conditions: $16^{\circ} \mathrm{C}$ for $30 \mathrm{~min}, 42^{\circ} \mathrm{C}$ for $30 \mathrm{~min}$, and $85^{\circ} \mathrm{C}$ for $5 \mathrm{~min}$. The obtained cDNA was diluted in 1:3 ratios and subjected to real-time PCR using a TaqMan amplicon specific assay probe under the following PCR cycle conditions: $95^{\circ} \mathrm{C}$ for $10 \mathrm{~min}, 95^{\circ} \mathrm{C}$ for $15 \mathrm{~s}$, and $60^{\circ} \mathrm{C}$ for $60 \mathrm{~s}[6]$.

\subsection{Statistical Analysis}

Data are expressed as means \pm SD. One way two-tailed ANOVA and Tukey post hoc tests were used for statistical analysis. $p<0.05$ was considered as statistically significant.

\section{Conclusions}

In conclusion, we have demonstrated that irradiation related changes are less pronounced in the RV as compared to the LV. Our results also suggest that treatment with aspirin and atorvastatin attenuate irradiation-induced up-regulation of myocardial Cx43 and PKCE signaling as well as miR-21 expression. Whether treatment related prevention or attenuation of irradiation-induced myocardial alterations at the early responsive period might help to prevent adverse late effects needs further investigations.

Acknowledgments: This study was supported by grants APVV-0241/11, APVV-15-0376 of Slovak Research and Development Agency and VEGA 2/0076/16, VEGA 2/0167/15 of Slovak Scientific Grant Agency and by EU Structural Fund ITMS 26230120006.

Author Contributions: Csilla Viczenczova: acquisition of data, data analysis/interpretation; Branislav Kura: acquisition of data, data analysis/interpretation; Tamara Egan Benova: acquisition of data, data analysis/interpretation; Chang Yin: acquisition of data, data analysis/interpretation; Rakesh C. Kukreja: formulation of the overall concept/design of experiments, editing of English language; Jan Slezak: formation of concept/design of experiment; Narcis Tribulova: formation of concept/design of experiment, critical revision of the manuscript, and approval of the article; Barbara Szeiffova Bacova: acquisition of data, data analysis/interpretation, approval of the article. 
Conflicts of Interest: The authors declare no conflict of interest.

\section{References}

1. Cuomo, J.R.; Sharma, G.K.; Conger, P.D.; Weintraub, N.L. Novel concepts in radiation-induced cardiovascular disease. World J. Cardiol. 2016, 8, 504-519. [CrossRef] [PubMed]

2. Slezak, J.; Kura, B.; Ravingerova, T.; Tribulova, N.; Okruhlicova, L.; Barancik, M. Mechanisms of cardiac radiation injury and potential preventive approaches. Can. J Physiol. Pharmacol. 2015, 27, 1-17. [CrossRef] [PubMed]

3. Simone, N.L.; Soule, B.P.; Ly, D.; Saleh, A.D.; Savage, J.E.; Degraff, W.; Cook, J.; Harris, C.C.; Gius, D.; Mitchell, J.B. Ionizing radiation-induced oxidative stress alters miRNA expression. PLoS ONE 2009, 4, e6377. [CrossRef] [PubMed]

4. Kura, B.; Babal, P.; Slezak, J. Implication of microRNAs in the development and potential treatment of radiation-Induced heart disease. Can. J. Physiol. Pharmacol. 2017, 95, 1236-1244. [CrossRef] [PubMed]

5. Zhu, H.; Fan, G.C. Role of microRNAs in the reperfused myocardium towards post-infarct remodelling. Cardiovasc. Res. 2012, 94, 284-292. [CrossRef] [PubMed]

6. Viczenczova, C.; Szeiffova Bacova, B.; Egan Benova, T.; Kura, B.; Yin, C.; Weismann, P.; Kukreja, R.; Slezak, J.; Tribulova, N. Myocardial connexin-43 and PKC signalling are involved in adaptation of the heart to irradiation-induced injury: Implication of miR-1 and miR-21. Gen. Physiol. Biophys. 2016, 35, $215-222$. [CrossRef] [PubMed]

7. Gürses, I.; Özeren, M.; Serin, M.; Yücel, N.; Erkal, H.S. Histopathological evaluation of melatonin as a protective agent in heart injury induced by radiation in a rat model. Pathol. Res. Pract. 2014, 210, 863-871. [CrossRef] [PubMed]

8. Amino, M.; Yoshioka, K.; Tanabe, T.; Tanaka, E.; Mori, H.; Furusawa, Y.; Zareba, W.; Yamazaki, M.; Nakagawa, H.; Honjo, H.; et al. Heavy ion radiation up-regulates connexin43 and ameliorates the arrhythmogenic substrates in rabbit hearts after myocardial infarction. Cardiovasc. Res. 2006, 72, 412-421. [CrossRef] [PubMed]

9. Amino, M.; Yoshioka, K.; Fujibayashi, D.; Hashida, T.; Furusawa, Y.; Zareba, W.; Ikari, Y.; Tanaka, E.; Mori, H.; Inokuchi, S.; et al. Year-long upregulation of connexin43 in rabbit hearts by heavy ion irradiation. Am. J. Physiol. Heart Circ. Physiol. 2010, 298, 1014-1021. [CrossRef] [PubMed]

10. Viczenczova, C.; Kura, B.; Chaudagar, K.K.; Szeiffova Bacova, B.; Egan Benova, T.; Barancik, M.; Knezl, V.; Ravingerova, T.; Tribulova, N.; Slezak, J. Myocardial connexin-43 is upregulated in response to acute cardiac injury in rats. Can. J. Physiol. Pharmacol. 2017, 95, 911-919. [CrossRef] [PubMed]

11. Song, J.; Yan, R.; Wu, Z.; Li, J.; Yan, M.; Hao, X.; Liu, J.; Li, S. ${ }^{13} \mathrm{~N}$-ammonia PET/CT detection of myocardial perfusion abnormalities in beagle dogs after local heart irradiation. J. Nucl. Med. 2017, 58, 605-610. [CrossRef] [PubMed]

12. Slezak, J.; Kura, B.; Babal, P.; Barancik, M.; Ferko, M.; Frimmel, K.; Kalocayova, B.; Kukreja, R.C.; Lazou, A.; Mezesova, L.; et al. Potential markers and metabolic processes involved in the mechanism of radiation-induced heart injury. Can. J. Physiol. Pharmacol. 2017, 95, 1190-1203. [CrossRef] [PubMed]

13. Shi, X.; Ding, M.; Dong, Z.; Chen, F.; Ye, J.; Wang, S.; Leonard, S.S.; Castranova, V.; Vallyathan, V. Antioxidant properties of aspirin: Characterization of the ability of aspirin to inhibit silica-induced lipid peroxidation, DNA damage, NF-kappaB activation, and TNF-alpha production. Mol. Cell. Biochem. 1999, 199, 93-102. [CrossRef] [PubMed]

14. Pignatelli, P.; Carnevale, R.; Pastori, D.; Cangemi, R.; Napoleone, L.; Bartimoccia, S.; Nocella, C.; Basili, S.; Violi, F. Immediate antioxidant and antiplatelet effect of atorvastatin via inhibition of Nox2. Circulation 2012, 126, 92-103. [CrossRef] [PubMed]

15. Lefer, A.M.; Scalia, R.; Lefer, D.J. Vascular effects of HMG CoA-reductase inhibitors (statins) unrelated to cholesterol lowering: New concepts for cardiovascular disease. Cardiovasc. Res. 2001, 49, 281-287. [CrossRef]

16. Webb, D.J.; Freestone, S.; Allen, M.J.; Muirhead, G.J. Sildenafil citrate and blood-pressure-lowering drugs: Results of drug interaction studies with an organic nitrate and a calcium antagonist. Am. J. Cardiol. 1999, 83, 21-28. [CrossRef] 
17. Cihák, R.; Kolár, F.; Pelouch, V.; Procházka, J.; Ostádal, B.; Widimský, J. Functional changes in the right and left ventricle during development of cardiac hypertrophy and after its regression. Cardiovasc. Res. 1992, 26, 845-850. [CrossRef] [PubMed]

18. Noorman, M.; van Rijen, H.V.; van Veen, T.A.; de Bakker, J.M.; Stein, M. Differences in distribution of fibrosis in the ventricles underlie dominant arrhythmia vulnerability of the right ventricle in senescent mice. Neth. Heart J. 2008, 16, 356-358. [CrossRef] [PubMed]

19. Szeiffová Bačová, B.; Egan Beňová, T.; Viczenczová, C.; Soukup, T.; Rauchová, H.; Pavelka, S.; Knezl, V.; Barančík, M.; Tribulová, N. Cardiac connexin-43 and PKC signaling in rats with altered thyroid status without and with omega-3 fatty acids intake. Physiol. Res. 2016, 65, 77-90.

20. Liu, J.; Zhu, H.; Yang, X.; Ge, Y.; Zhang, C.; Qin, Q.; Lu, J.; Zhan, L.; Cheng, H.; Sun, X. MicroRNA-21 is a novel promising target in cancer radiation therapy. Tumour Biol. 2014, 35, 3975-3979. [CrossRef] [PubMed]

21. Rezaeyan, A.; Haddadi, G.H.; Hosseinzadeh, M.; Moradi, M.; Najafi, M. Radioprotective effects of hesperidin on oxidative damages and histopathological changes induced by $\mathrm{X}$-irradiation in rats heart tissue. J. Med. Phys. 2016, 41, 182-191. [CrossRef] [PubMed]

22. Sieber, F.; Muir, S.A.; Cohen, E.P.; Fish, B.L.; Mäder, M.; Schock, A.M.; Althouse, B.J.; Moulder, J.E. Dietary selenium for the mitigation of radiation injury: Effects of selenium dose escalation and timing of supplementation. Radiat. Res. 2011, 176, 366-374. [CrossRef] [PubMed]

23. Kura, B.; Bagchi, A.S.; Akolkar, G.; Singal, P.K.; Slezak, J. Myocardial changes after mediastinal irradiation in rats: Molecular mechamisms and potential targets to minimize the adverse effects. In Adaptation Biology and Medicine; Kawai, Y., Hargens, A.R., Singal, P.K., Eds.; Narosa Publishing House Ltd.: New Delhi, India, 2017; pp. 93-122.

24. Smyth, J.W.; Hong, T.T.; Gao, D.; Vogan, J.M.; Jensen, B.C.; Fong, T.S.; Simpson, P.C.; Stainier, D.Y.; Chi, N.C.; Shaw, R.M. Limited forward trafficking of connexin 43 reduces cell-cell coupling in stressed human and mouse myocardium. J. Clin. Investig. 2010, 120, 266-279. [CrossRef] [PubMed]

25. Egan Benova, T.; Szeiffova Bacova, B.; Viczenczova, C.; Diez, E.; Barancik, M.; Tribulova, N. Protection of cardiac cell-to-cell coupling attenuate myocardial remodeling and proarrhythmia induced by hypertension. Physiol. Res. 2016, 65, 29-42.

26. Tribulova, N.; Szeiffova Bacova, B.; Benova, T.; Viczenczova, C. Can we protect from malignant arrhythmias by modulation of cardiac cell-to-cell coupling? J. Electrocardiol. 2015, 48, 434-440. [CrossRef] [PubMed]

27. Su, F.; Zhao, L.; Zhang, S.; Wang, J.; Chen, N.; Gong, Q.; Tang, J.; Wang, H.; Yao, J.; Wang, Q.; et al. Cardioprotection by PI3K-mediated signaling is required for anti-arrhythmia and myocardial repair in response to ischemic preconditioning in infarcted pig hearts. Lab. Investig. 2015, 95, 860-871. [CrossRef] [PubMed]

28. Jeyaraman, M.M.; Srisakuldee, W.; Nickel, B.E.; Kardami, E. Connexin43 phosphorylation and cytoprotection in the heart. Biochim. Biophys. Acta 2012, 1818, 2009-2013. [CrossRef] [PubMed]

29. Thum, T.; Gross, C.; Fiedler, J.; Fischer, T.; Kissler, S.; Bussen, M.; Galuppo, P.; Just, S.; Rottbauer, W.; Frantz, S.; et al. MicroRNA-21 contributes to myocardial disease by stimulating MAP kinase signalling in fibroblasts. Nature 2008, 456, 980-984. [CrossRef] [PubMed]

30. Qiang, B.; Toma, J.; Fujii, H.; Osherov, A.B.; Nili, N.; Sparkes, J.D.; Fefer, P.; Samuel, M.; Butany, J.; Leong-Poi, H.; et al. Statin therapy prevents expansive remodeling in venous bypass grafts. Atherosclerosis 2012, 223, 106-113. [CrossRef] [PubMed]

31. Fabian, C.J.; Kimler, B.F.; Hursting, S.D. Omega-3 fatty acids for breast cancer prevention and survivorship. Breast Cancer Res. 2015, 17, 62. [CrossRef] [PubMed]

(C) 2018 by the authors. Licensee MDPI, Basel, Switzerland. This article is an open access article distributed under the terms and conditions of the Creative Commons Attribution (CC BY) license (http:// creativecommons.org/licenses/by/4.0/). 